\title{
LAF237 Enhances Glucose Tolerance and Graft $\beta$-Cell Mass in Diabetic Mice Transplanted with Sufficient Numbers of Islets
} Jyuhn-Huarng Juang1, Chien-Hung Kuo1, Chen-Yi Chen"1, Chen-Wei Kao', Chiung-Tong Chen²

${ }^{1}$ Chang Gung University and Memorial Hospital and ${ }^{2}$ National Health Research Institutes, Taiwan

\section{Background}

Dipeptidyl peptidase-4 (DPP-4) inhibitors increase circulating levels of glucagon-like peptide1 (GLP-1) and glucose-dependent insulino-tropic polypeptide (GIP) which can promote beta-cell proliferation and survival.

\section{Objective}

This study tested if DPP-4 inhibition with LAF237 is beneficial for diabetic recipients with a marginal or sufficient number of islets.

\section{Methods and Materials}

- Animals: Male inbred C57BL/6 mice, aged 6-8 weeks, were used as donors and recipients. Recipients were made diabetic by STZ $200 \mathrm{mg} / \mathrm{kg}$ ip.

- Islet isolation and purification: by collagenase digestion and density gradient

- Islet transplantation: 150 (Tx-150) or 300 (Tx-300) isolated islets were implanted under the left kidney capsule of each C57BL/6 mouse.

- LAF237 treatment: 10 mg/kg/day po for 6 weeks

- Recipients' metabolic parameters: blood glucose, body weight and intraperitoneal glucose tolerance test (IPGTT) were measured during 6 weeks

- Islet grafts were removed at 6 weeks for $\beta$-cell mass and insulin content.

\section{Results}

(I) Blood Glucose Changes after Transplantation
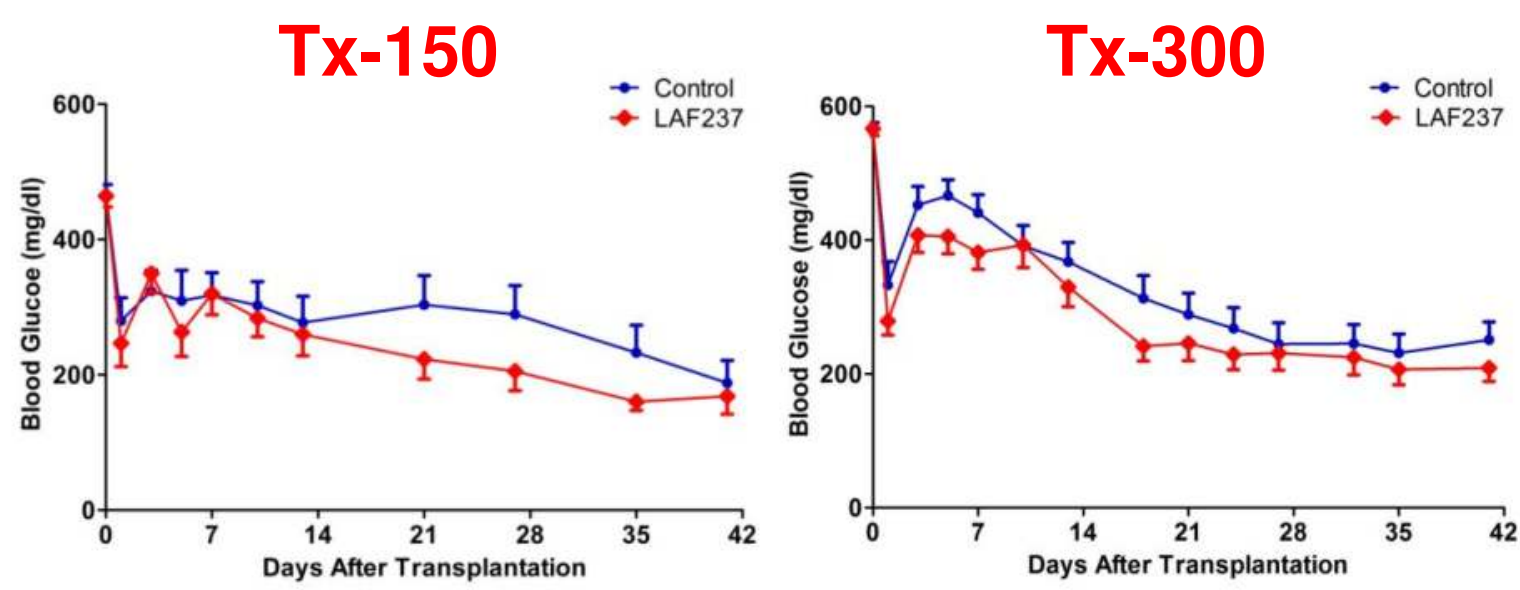

(II) Body Weight Changes after Transplantation

Tx-150

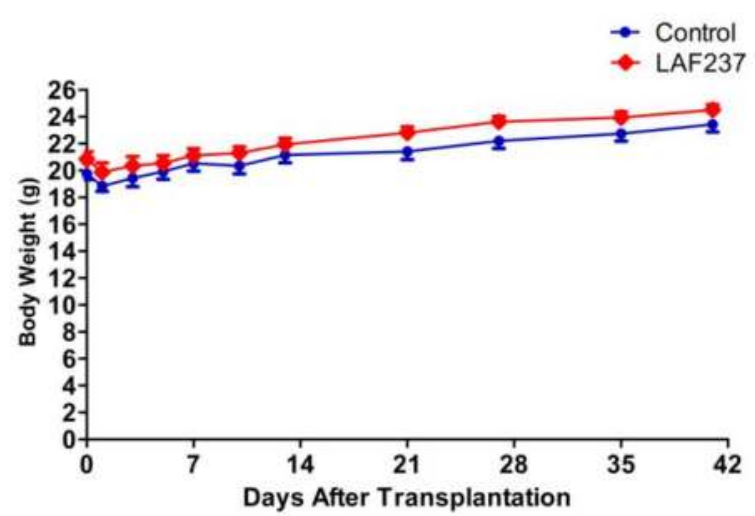

(III) Intraperitoneal Glucose Tolerance Test

Tx-150

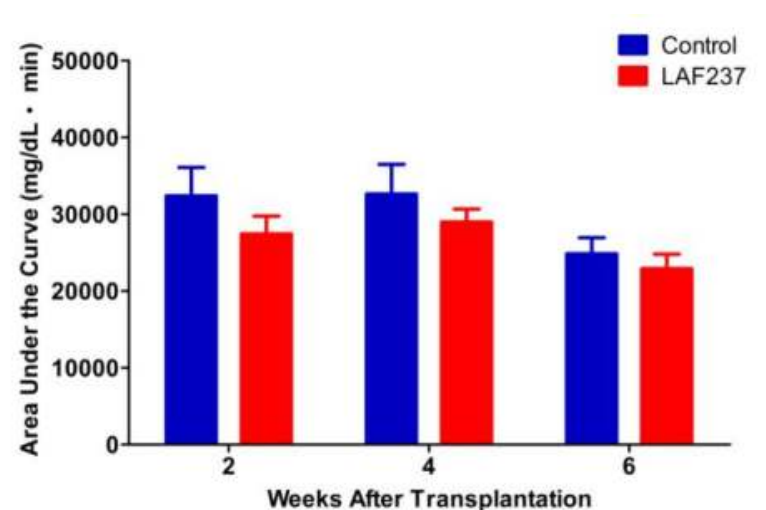

(IV) Graft $\beta$-Cell Mass

$\mathrm{Tx}-150$
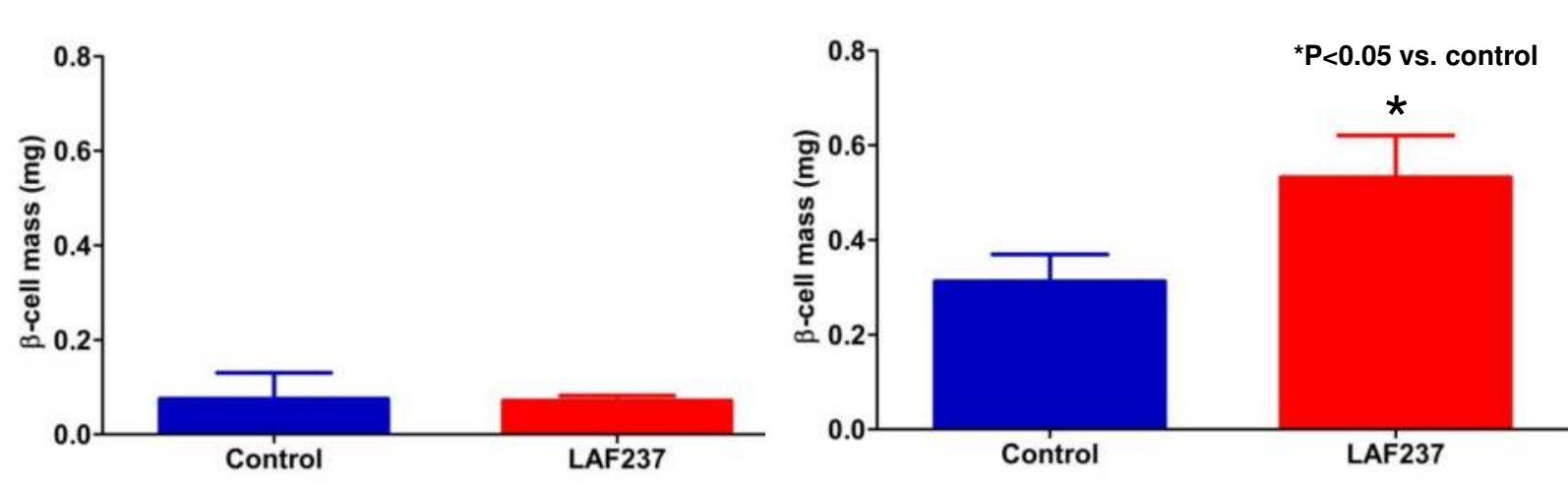

(V) Graft Insulin Content
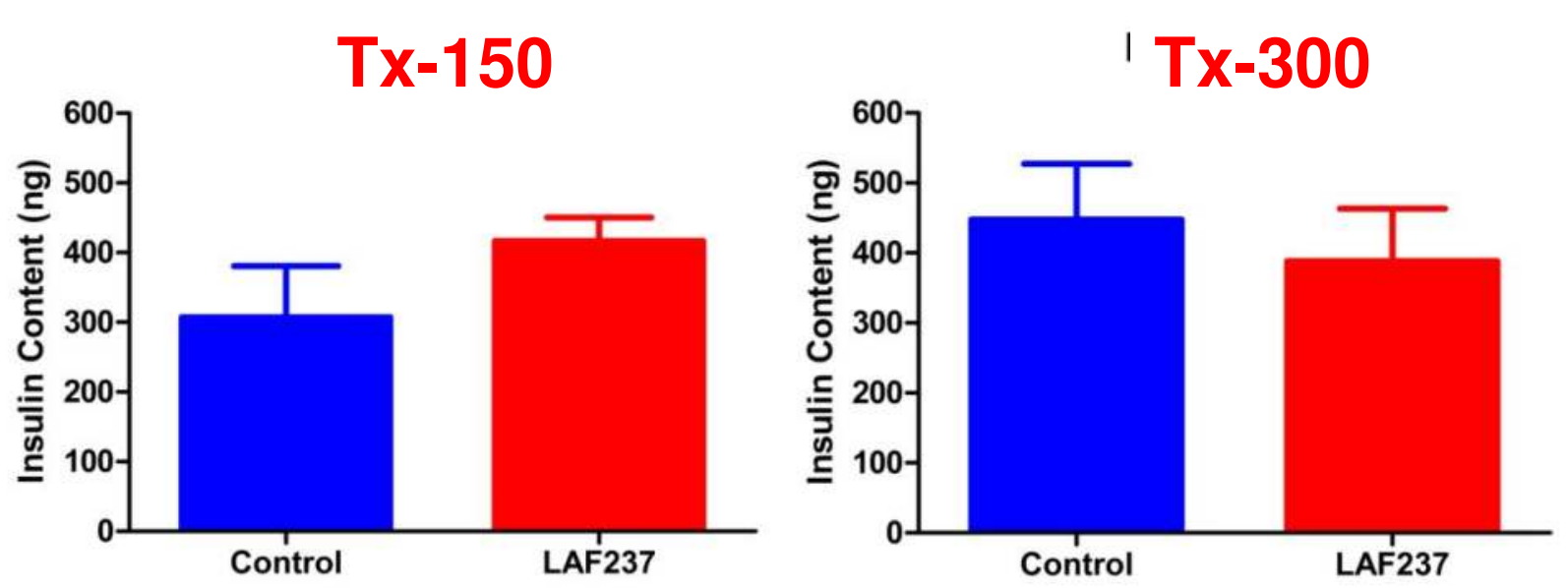

\section{Conclusion}

LAF237 treatment improves transplantation outcome and expands graft $\beta$-cell mass in diabetic mice transplanted with a sufficient but not marginal number of islets. 